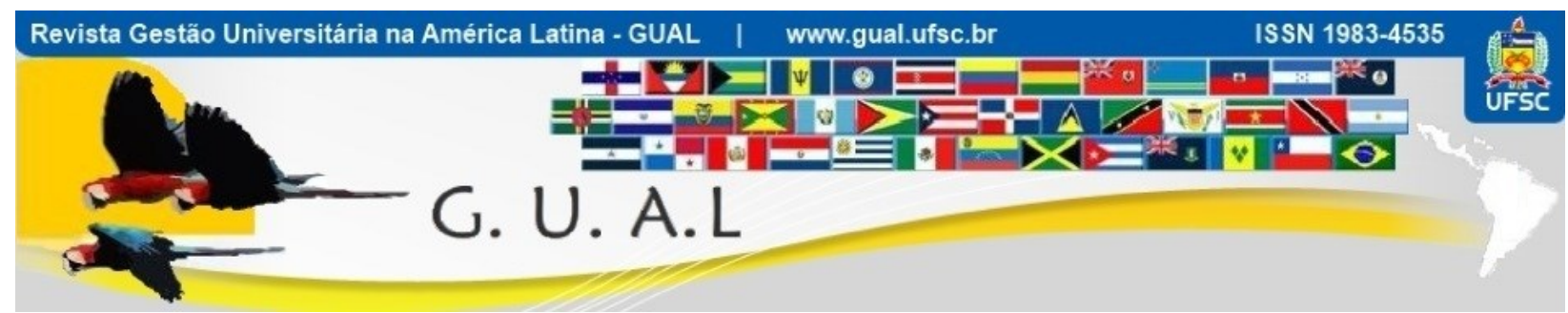

DOI: http://dx.doi.org/10.5007/1983-4535.2014v7n2p198

\title{
ENSINO DO EMPREENDEDORISMO SOB A ÓTICA DE ALUNOS E PROFESSORES DO CURSO DE ADMINISTRAÇÃO DE UMA INSTITUIÇÃO DE ENSINO SUPERIOR (IES) PRIVADA EM MINAS GERAIS
}

\section{ENTREPRENEURSHIP EDUCATION FROM THE PERSPECTIVE OF STUDENTS AND PROFESSORS OF DIRECTORS OF A HIGHER EDUCATION INSTITUTION (HEI) PRIVATE IN MINAS GERAIS}

Solange Carvalho Moreira Rodrigues, Mestra Faculdade Novos Horizontes sec-diretoria@unihorizontes.br

Marlene Catarina Oliveira Lopes Melo, Doutora Faculdade Novos Horizontes lenemelo@unihorizontes.br

Ana Lucia Magri Lopes, Mestra Faculdade Novos Horizontes ana.lopes@unihorizontes.br

Recebido em 14/novembro/2013

Aprovado em 02/maio/2014

Sistema de Avaliação: Double Blind Review

Esta obra está sob uma Licença Creative Commons Atribuição-Uso. 


\title{
RESUMO
}

Este artigo objetiva verificar a prática didático-pedagógica na área do empreendedorismo e sua interferência na propensão às atividades empreendedoras na percepção de alunos e professores do curso de Administração de uma Instituição de Ensino Superior (IES) privada localizada no Vale do Aço-MG. Este estudo de caso qualitativo descritivo teve como sujeitos de pesquisa quinze alunos do oitavo período do curso de Administração e quatro professores do referido curso, definidos por acessibilidade. Os dados foram coletados por meio de entrevistas semiestruturadas e análise documental. Posteriormente, foram ordenados, tabulados e classificados em unidades temáticas buscando-se os significados e a essência nos relatos. Evidenciou-se que a prática didático-pedagógica adotada na IES pesquisada propicia aos estudantes condições ao processo de empreender indicando a possibilidade de ensino formal do empreendedorismo. Como um fenômeno "multifacetado e multidisciplinar" demonstra não ser excludente uma via ou outra de aprendizado, exigindo no ambiente escolar, atividades práticas como nos moldes da Empresa-Ação ou de empresas simuladas. Do ponto de vista institucional destacam-se algumas contribuições para o campo como a adoção de mecanismos de apoio ao ensino, a realização de parcerias entre os atores institucionais privados e públicos, empresas de transferência de tecnologia ofertando condições estruturais, além das incubadoras.

Palavras-chave: Empreendedorismo. Ensino de empreendedorismo. Prática didáticopedagógica.

\begin{abstract}
This article aims to verify the didactic-pedagogic in the area of entrepreneurship and its interference in the propensity to entrepreneurial activities in the perception of students and professors of directors of a Higher Education Institution (HEI) privately located in the Steel Valley-MG. This qualitative case study was descriptive as research subjects fifteen students in the eighth period course of administration and the teachers of the said course, defined by accessibility. Data were collected through semi-structured interviews and documentary analysis. Later, they were ordered, tabulated and classified into thematic units looking up the meanings and essence in the reports. It was evident that the didactic-pedagogic adopted in IES provides students researched conditions the process of undertaking indicating the possibility of formal teaching of entrepreneurship. Phenomenon as a "multifaceted and multidisciplinary" demonstrates not be exclusionary one way or another learning, requiring the school environment, practical activities as modeled Company-Action or simulated companies. From the institutional point of view highlight some contributions to the field as the adoption of mechanisms to support education, the establishment of partnerships between the public and private institutional actors, companies offering technology transfer framework conditions, in addition to the incubators.
\end{abstract}

Keywords: Entrepreneurship. Entrepreneurship Education. Practice didactic-pedagogic. 


\section{INTRODUÇÃO}

O empreendedorismo, enquanto tema das ciências sociais aplicadas, tem despertado interesse de pesquisadores, transformando-se em objeto de estudos nas diversas áreas do conhecimento. Estes estudos objetivam o fortalecimento de um arcabouço teórico, a mitigação de equívocos acerca do fenômeno do empreendedorismo e a compreensão do processo empreendedor na sociedade (BORGES; FILION; SIMARD, 2008; MELO et al, 2009; GEM, 2012).

O empreendedorismo é um fenômeno antigo e apesar da abundância de estudos, segundo Meurer (2003), Souza et al, (2006), Hisrich, Peters e Shepherd (2009), Saraiva e Souza (2009), não há uma teoria consolidada e nem uma definição única para o termo. Estes autores consideram que o tema recebe conceituação tão diversa quanto são os seus atores sociais.

Schumpeter (1997) analisou a atuação do empreendedor como um fenômeno fundamental para o desenvolvimento econômico, seja quando um indivíduo introduz inovações, seja em termos de criação de novos produtos e novos mercados ou, ainda, de novos métodos e processos produtivos.

Segundo Ferreira; Ramos e Gimenez (2006) o empreendedorismo tem por finalidade promover o aproveitamento dos recursos sociais, materiais e cognitivos, compreendendo os modelos de tomada de decisão, percepção de oportunidades e demais habilidades envolvidas na combinação de recursos. Os autores relacionam ainda, o empreendedorismo com a Teoria dos Sistemas desenvolvida pelo biólogo Bertalanffy (1973), segundo a qual os sistemas estão em toda parte e interagem com o ambiente onde se inserem por meio de entradas, saídas e realimentação visando à sua própria manutenção.

Transpondo estes conceitos para o campo do empreendedorismo, a entrada seria o desejo de realização, a busca de satisfação das necessidades combinada aos recursos materiais e humanos. O processamento ou a relação entre esses fatores resultaria na criação - ou saída do que se pretendia, e ainda para compreender o fenômeno do empreendedorismo este deve ser considerado de forma integrada associando-os aos aspectos culturais e ao modo de pensar (FERREIRA; RAMOS; GIMENEZ, 2006; OLIVEIRA, 2006).

Alguns estudiosos apontam que o empreendedorismo pode ser ensinado e que as pessoas podem desenvolver características, competências e habilidades para se tornarem empreendedoras, com o foco no ensino não apenas instrumental, mas considerando-se os 
atributos do ser (DAVID, et al, 2001; FILION, 2003; DOLABELA, 2008). Outros, como Maculan (2005), argumentam que para ensinar o empreendedorismo, bem como pesquisar sobre este tema é necessário distinguir os tipos de empreendimentos existentes pelas posturas de seus atores, ou seja, o empreendedor que inova e o criador de empresa por necessidade de sobrevivência.

Diante do exposto e considerando que o empreendedorismo tem recebido estímulos no âmbito do ensino, torna-se instigante compreender se estudantes que ingressaram no curso de Administração se vêem potencialmente capazes de empreender.

Este estudo teve como objetivo verificar a prática didático-pedagógica na área do empreendedorismo e sua interferência na propensão às atividades empreendedoras na percepção de alunos e professores do curso de Administração de uma Instituição de Ensino Superior (IES) privada localizada no Vale do Aço - MG.

O artigo está estruturado em seis seções a partir desta introdução. A segunda seção apresenta o referencial teórico que versa sobre as características do empreendedorismo no Brasil, bem como as dimensões empreendedoras e o ensino do empreendedorismo. A terceira seção traz os procedimentos metodológicos adotados nesta pesquisa e, na quarta seção apresenta-se uma contextualização da instituição pesquisada e análise dos dados. Na quinta seção apresenta-se as considerações finais seguida pelas referências.

\section{REFERENCIAL TEÓRICO}

\subsection{CARACTERÍSTICAS DO EMPREENDEDORISMO NO BRASIL}

O Brasil é apontado como um dos países onde o empreendedorismo apresenta elevados índices, alcançando, conforme pesquisa anual realizada pelo Global Entrepreneurship Monitor (GEM, 2012) 15,4 \% na Taxa de Empreendedores em Estágio Inicial (TEA). Transformando este percentual em número absoluto, estima-se que, em 2012, 18 milhões de indivíduos entre 18 e 64 anos estavam envolvidos na criação ou administração de um negócio em estágio inicial (nascente ou novo).

Ao longo de dez anos o Brasil apresentou média de $13 \%$ de sua população economicamente ativa empreendendo, sendo que o maior percentual de empreendedores $(19,2 \%)$ concentra-se na faixa etária de 25 a 34 anos, caracterizado por um empreendedorismo jovem (GEM, 2012). Apesar disso, a percepção das condições para o empreendedor no Brasil não são favoráveis, apontando aspectos limitantes das atividades empreendedoras ainda que 
as condições macroeconômicas para empreender sejam propícias devido à estabilidade da economia e ao dinamismo do mercado.

Segundo o Relatório do GEM (2012, p. 10) as limitações para a ação de empreender no país estão relacionadas com "o nível de educação empreendedora no ensino fundamental e médio; o nível de educação empreendedora no ensino técnico e superior; as políticas governamentais: burocracia e impostos; as políticas governamentais concretas (prioridades e suporte); e, as Ações e esforços dos agentes públicos para promover as relações e colaborações comerciais como feiras e cursos, dentre outros.

A pesquisa do GEM (2012) avaliou, também, junto aos empreendedores pesquisados, o atributo da inovação, ou seja, quando o produto ou serviço pode ser considerado novo perante os consumidores. Para os empreendimentos iniciais, os resultados são bastante conservadores: a grande maioria dos negócios $(98,9 \%)$ no Brasil, lida com conhecimentos que ninguém considera novo. De outro lado, 1,1\% dos pesquisados afirmaram que "alguns considera novo". Verifica-se, dessa forma, a importância e a oportunidade para ampliação e promoção do empreendedorismo inovador.

Quanto à mortalidade das empresas no Brasil, de cada "100 empreendimentos criados, 73 sobrevivem aos primeiros dois anos de atividade", indicando uma evolução positiva nos índices de sobrevida das empresas (SEBRAE, 2011, p. 4).

A despeito destes dados, Dolabela (2010) enfatiza que ainda são necessárias ações para o desenvolvimento do empreendedorismo no Brasil, como o apoio aos empreendedores emergentes. Isso é corroborado pela própria pesquisa do GEM (2009), que demonstra, desde o início das atividades das pesquisas anuais neste país até o ano de 2008, um alto índice de empreendedorismo por necessidade.

\section{DIMENSÕES EMPREENDEDORAS E O ENSINO DO EMPREENDEDORISMO}

As respostas obtidas acerca do conceito de empreendedorismo no estudo realizado por Ferreira, Ramos e Gimenez (2006) em universidades brasileiras e norte-americanas foram agrupadas em cinco dimensões: criação de novos negócios, gestão de empresas, características individuais, promoção da inovação e visão generalista, que engloba os aspectos anteriores. Isso demonstra uma variedade de entendimento desse fenômeno.

Tomando-se apenas a primeira dimensão, sabe-se que o processo de criação de empreendimentos não é linear, existindo diferentes configurações de organizações em 
diferentes estágios de desenvolvimento e que recrutam conhecimentos de todas as áreas do saber (BORGES; FILION; SIMARD, 2008).

De acordo com Hisrich, Peters e Shepherd, (2009, p. 30), as definições de empreendedor varia conforme o prisma de quem conceitua, podendo haver um consenso em relação à necessidade de certas atitudes, como tomar iniciativa, organizar e reorganizar mecanismos sociais e econômicos a fim de transformar recursos e situações para proveito prático individual ou de um grupo, tendo a capacidade de aceitar o risco ou o fracasso. Para estes autores, o empreendedorismo pode ser considerado um "processo de criar algo novo com valor, assumindo os riscos financeiros, psíquicos e sociais correspondentes e recebendo as consequentes recompensas da satisfação e da independência financeira e pessoal".

Assim, o atributo da inovação se evidencia, corroborando o pensamento schumpeteriano de que o que constitui o empreendedor é a realização de inovações.

O empreendedorismo pode ser considerado uma atividade eminentemente social, pois, "quase todas as pesquisas sobre empreendedorismo indicam que é mais provável que grupos obtenham sucesso do que empreendedores individuais" (BRUSH; HART; GREENE, 2002, p. 28), conforme pesquisa realizada por Borges, Filion e Simard (2008) em Québec, no Canadá, ao mostrarem que a maior parte das empresas estudadas foram criadas por equipes de empreendedores e não individualmente.

Cunningham e Lischeron (1991) apontam que na "Escola das Grandes Figuras", o empreendedor isoladamente é colocado em evidência, enquanto outros estudos demonstram um índice mais elevado do empreendedorismo por equipe (BORGES; FILION; SIMARD, 2008). Para estes autores o empreendedorismo vem sendo construído em pesquisas que consideram o empreendedor individual e, em contraponto, a crescente ocorrência de empreendedorismo por equipe representa um desafio para este campo. Esses argumentos, colocados quanto ao processo empreendedor, parecem indicar uma necessidade de interação entre as pessoas, principalmente ao constituir empresas.

Em relação ao empreendedor, o seu modo de pensar é peculiar, e frequentemente toma decisões que envolvem altos riscos, dispondo de pouco tempo para decidir e nem sempre recorrendo a soluções racionais. Quanto ao ambiente e ao processo de tomada de decisões, o empreendedor precisa, às vezes, executar, pensar em como se adaptar e aprender com os erros (DRUCKER, 2008; HISRICH; PETERS; SHEPHERD, 2009). 
Outro enfoque dado ao fenômeno empreendedor, segundo destacado por Saraiva e Souza (2009), refere-se ao empreendedorismo como decorrente de mudanças ocorridas no mercado de trabalho e que colocam em dúvida a relação convencional de emprego, das exigências de qualificação do trabalhador e das transformações estruturais por que passa a economia mundial. Diante de um quadro de incertezas quanto ao próprio emprego e de oportunidades a serem exploradas, o indivíduo ou o empreendedor passaria a ter estímulos para agir.

Em relação ao ensino do empreendedorismo Schmidt, Domingues e Hoeltgebaum (2005) e, Saraiva e Souza (2009) argumentam que ainda não está claro, na teoria e na prática, se este já nasce nesta condição, dotado de uma capacidade excepcional para vislumbrar e aproveitar uma oportunidade ou se aprende por meio de ensino formal, cursos e treinamentos. Saraiva e Souza (2009, p. 11) salientam que "o empreendedorismo é representado como um elemento necessário na formação de administradores e que o empreendedor possui características especiais, sobre as quais paira certa dúvida a respeito da possibilidade de ensino".

Não obstante, Dolabela (2006), Souza e Guimarães (2006) e Pereira (2010) indicam que as instituições de ensino devem desempenhar um papel de agente promotor, disseminando uma cultura empreendedora em todos os níveis. Neste sentido, Oliveira (2006) diz ser necessário criar, aplicar e disponibilizar mecanismos integradores, uma vez que o evento empreendedor não é um fator isolado e as instituições de ensino constituem uma organização que reúne condições necessárias para promovê-lo.

Desse modo, ação e reflexão sobre o desempenho exercido por essas instituições enquanto atoras de desenvolvimento regional, no âmbito do ensino do empreendedorismo, também revelam-se importantes.

Em um modelo de ensino Resende, Dib e Leite (2005, p. 43-44) propõem que a contribuição das disciplinas de empreendedorismo deva ser orientada para o "sujeito", com foco no desenvolvimento humano ao invés de "objeto", a mera criação de produtos ou serviços pelo potencial empreendedor. Para estes autores, "a contribuição do ensino de empreendedorismo é muito mais estruturante do que o específico incentivo à criação de empresas", despertando no aluno uma busca de realização pessoal e profissional. Alegam, ainda, que "a formação de empreendedorismo vem absorvendo como missão esse 
entendimento de desenvolvimento do sujeito, que deve necessariamente ser inquirido pelo seu sonho, sua causa e sua missão".

Em uma ótica pragmática, Oliveira (2005) argumenta que o interesse pelo tema do empreendedorismo no ambiente escolar pode ser atribuído à necessidade de proporcionar aos estudantes novas formas de inserção profissional em uma sociedade altamente competitiva.

Assim, uma instituição que assume o seu papel de agente articulador, implementando o ensino desse tema de forma integrada com suporte à inovação, à pesquisa com transferência de tecnologia e recursos financeiros pode contribuir para que o educando descubra o seu potencial empreendedor.

\section{PROCEDIMENTOS METODOLÓGICOS}

Trata-se de um estudo de caso de natureza qualitativa e descritiva. Para Chizzoti (2003, p. 230), "as pesquisas qualitativas tendem para o estudo de questões delimitadas, locais, apreendendo os sujeitos no ambiente natural em que vivem nas suas interações interpessoais e sociais, nas quais tecem os significados e constroem a realidade". Neste sentido, estabeleceu-se certa proximidade com os sujeitos da pesquisa na instituição estudada, procedendo-se à coleta de dados por meio de entrevistas semiestruturadas e análise documental.

Como o empreendedorismo, na perspectiva de autores como David et al, (2001) e Ferreira, Ramos e Gimenez (2006) é considerado um fenômeno cujos paradigmas estão em construção, carecendo conforme Saraiva e Souza (2009), de consenso quanto à sua definição enquanto ciência, considera-se a abordagem qualitativa adequada para esta investigação.

A unidade de análise foi o curso de Administração de uma Instituição de Ensino Superior privada localizada no Vale do Aço - MG e, os sujeitos desta pesquisa foram quinze estudantes do oitavo período e quatro professores deste mesmo curso, atuantes na área do empreendedorismo, definidos por acessibilidade. Os alunos do último período foram escolhidos por terem cursado disciplinas específicas e correlatas ao desenvolvimento de empresas e organizações.

Utilizou-se dois roteiros distintos de perguntas, sendo um para os alunos e outro para os professores, com perguntas inter-relacionadas e elaboradas com vistas a atender o objetivo da pesquisa. Somados à análise documental procurou-se valer de mais de uma fonte de 
evidência para elucidar as indagações da pesquisa, cujos resultados são apresentados adiante (ALVES-MAZZOTTI; GEWANDSZNAJDER, 2004).

Segundo Melo et al, (2007, p. 70) “[...] o tratamento dos dados está fortemente vinculado à sua análise [...]" incluindo-se a [...] "preparação, tabulação quantitativa e análise ou categorização temática".

Apresenta-se, assim, nos resultados desta pesquisa os temas mais destacados dos depoimentos, os significados atribuídos pelos entrevistados em consonância ao que se pretendeu investigar, confrontados com os fundamentos encontrados na literatura.

\section{APRESENTAÇÃO DOS RESULTADOS}

O desenvolvimento econômico e o crescimento populacional na região do Vale do Aço, onde está localizada a Instituição de Ensino Superior (IES) pesquisada, foram favorecidos pela abundância de minério de ferro em Itabira e pela existência da ferrovia Vitória-Minas. Essas condições propiciaram a criação da siderúrgica Companhia Aços Especiais Itabira - Acesita, na cidade de Timóteo no ano de 1944 (atualmente Aperam), e a criação de outra siderúrgica - Usiminas - na cidade de Ipatinga, em 1956.

Em meados da década de 60, mais precisamente em 1965, a IES foi criada pela Congregação Religiosa Missionários do Trabalho e o curso de Administração foi implantado no ano de 1977, sendo reconhecido pelo Ministério da Educação e Cultura (MEC) em 1983.

No ano 2000 optou-se por implementar um novo curso de Administração, que atendesse a demanda social no que tange ao empreendedorismo. Atualmente, o regime escolar do curso é seriado semestral, sendo integralizado em no mínimo 4 anos, distribuídos em 8 semestres, com carga horária curricular total corresponde a 3.000 horas, dimensionada em 200 dias letivos.

O Projeto Pedagógico do Curso (PPC) está estruturado a partir de uma visão interdisciplinar e multidisciplinar, possibilitando o desenvolvimento dos conteúdos com articulação entre a teoria e a prática (UNILESTE, 2010).

Em especial, as disciplinas Comportamento Empreendedor e Gerencial, ofertada no $5^{\circ}$ período do curso, e Criação de Empresas e Negócios, no $6^{\circ}$ período, estão objetivamente, ligadas ao empreendedorismo, mas não somente elas, pois se trata do aprendizado do fenômeno de um processo dinâmico e complexo (PESSOA; GONÇALVES, 2004; ANTONELLO; DUTRA, 2005; FERREIRA; RAMOS; GIMENEZ, 2006; MARTENS; 
FREITAS, 2008). No PPC observa-se ainda, a existência de quatro disciplinas denominadas "Desenvolvimento Empresarial-I ao IV", ofertadas a partir do $5^{\circ}$ período, que também estão ligadas ao empreendedorismo. Na disciplina Desenvolvimento Empresarial II ( $6^{\circ}$ período), os alunos vivenciam em laboratório "situações que envolvem as empresas permitindo colocar em prática todo o conteúdo desenvolvido no curso" (PPCGA, 2010, p. 100). Na disciplina Desenvolvimento Empresarial III ( $7^{\circ}$ período), os alunos realizam vivências "estudo e aplicação prática do processo de consultoria empresarial dentro do contexto das micros e pequenas empresas da região" (PPCGA, 2010, p. 105).

Quanto ao perfil do grupo de 15 alunos entrevistados, a média de idade apresentada foi de 29,3 anos. Sendo alunos do último período do curso, a idade é relativamente superior à apresentada atualmente pela maioria dos que ingressam no curso, que se situam na faixa de 18 a 24 anos. A renda familiar média do grupo de alunos entrevistados é de $\mathrm{R} \$ 4.100,00$, sendo que oito alunos possuem empregos formais, seis não trabalham e um possui uma microempresa, além de dar suporte ao negócio da família.

A motivação mais citada pelos discentes entrevistados para cursar Administração foi a de que o curso abre um "leque de oportunidades" e permite estudar vários módulos (disciplinas) "sem se prender a uma determinada área" (47\%), bem como motivações relacionadas ao estudo do empreendedorismo. Outros 33\% dos alunos entrevistados disseram ter escolhido o curso porque se identificam com a área da Administração e $26 \%$ dos entrevistados ingressaram com a pretensão de desenvolver um negócio próprio, buscar autonomia e aprimorar a empresa familiar.

Segundo Pessoa e Gonçalves (2004) e Martens e Freitas (2008), a aprendizagem do empreendedorismo é mais efetiva ao se propiciar ao educando a aplicação prática dos conhecimentos teóricos adquiridos. Oliveira (2006) explica que os mecanismos de ensino do empreendedorismo devem ser integradores, ultrapassando os limites da escola e alcançando as esferas públicas e privadas.

Dois dos quatro professores entrevistados mencionaram a preocupação com a interdisciplinaridade e o encadeamento de disciplinas visando possibilitar aos educandos a aquisição de competências para construir uma empresa, caso assim o deseje. Na percepção de $85 \%$ dos alunos entrevistados e de um dos professores entrevistados, a adoção de dinâmicas e jogos de empresas são elementos que poderiam contribuir ainda mais para o processo de aprendizagem do empreendedorismo, além da própria atividade da "Empresa-Ação" existente. 
Outro professor entrevistado argumentou que a disciplina Plano de Negócios, deveria ser cursada antes da disciplina Comportamento Empreendedor e Gerencial, para que o aluno tenha mais aproveitamento ao realizar a atividade prática da "Empresa-Ação" e, após as disciplinas da área financeira como Contabilidade para Administradores e Administração Financeira e Orçamentária, para que ele próprio tenha capacidade de construir a parte financeira do plano. Quanto ao Plano de Negócios, Andreassi e Fernandes (2010), argumentam que os Business Plans não são vitais para as etapas iniciais de um empreendimento. Segundo estes autores, no Brasil e no mundo os negócios novos seguem a prática da "tentativa e erro" ou "fazendo e aprendendo", invertendo a lógica causal de primeiro definir-se a proposta do negócio, a segmentação de mercado, planos de marketing e posicionamento de produtos ou serviços. Ainda que esta seja uma posição correta, dependendo do tipo de negócio que se inicia, do volume de recursos materiais e financeiros empregados, um planejamento de qualidade em empresas desenvolvidas não são dispensados (ANDREASSI; FERNANDES, 2010; LUECKE, 2010).

As atividades de cunho mais prático no ensino do empreendedorismo, são particularmente importantes e estão de acordo com a abordagem tridimensional e experiencial vista em Pessoa e Gonçalves (2004), e com a aprendizagem cooperativa e experiencial trabalhada por Antonello e Dutra (2005), entre outros autores.

Quanto à percepção do aprendizado sobre empreendedorismo, o desenvolvimento das habilidades necessárias, o uso de ferramentas e as percepções teóricas sobre este tema, os alunos entrevistados tiveram a possibilidade de fazer referência a vários conceitos. A inovação ou o "saber inovar" foi o requisito mais citado, representando $33 \%$ das respostas dos alunos entrevistados e vista como um atributo para vencer a concorrência. De fato, a inovação pode ser considerada a essência do empreendedorismo, sendo extensivamente citada na literatura e estando, também, ligada ao atributo da criatividade.

Os alunos entrevistados citaram, ainda, a "visão de futuro" do empreendedor, sua capacidade de antecipar-se quanto a uma possível ameaça ao seu negócio e as estratégias usadas para atuar no mercado:

[...] A questão da inovação pra mim é muito importante. E também da iniciativa [...] porque não adianta você só pensar e não ter assim, a ação [...] e se você não quiser empreender de uma forma inovadora é praticamente criar uma coisa que já existe, aí estará apenas copiando (Aluno 5). 
Quanto à percepção do processo empreendedor, as respostas foram variadas e evidenciaram não apenas atitudes comportamentais, mas também habilidades e conhecimentos em que $27 \%$ dos alunos entrevistados disseram que os empreendedores devem ter garra, persistência, saber relacionar-se com as pessoas e estabelecer networking. As demais respostas referiram-se à capacitação e motivação dos empregados e à necessidade de ser ético e idôneo, além de comprometido, organizado e bom planejador:

[...] Fazer networking, uma boa rede de contatos, capacitar e motivar os funcionários, investir em mudança. A empresa fica com um foco ali [em um único segmento] e se acaba aquele ramo ou o mercado fica saturado, a empresa acaba fechando por falta de inovação [...] ou adaptação também a outros produtos e serviços [mercados] (Aluno 12).

Quanto à forma de atuação, quase metade dos alunos entrevistados (46\%) responderam que o empreendedor "sabe identificar oportunidades" e "permanece atento ao mercado, às oportunidades e às ameaças". Um número expressivo de alunos entrevistados (40\%) mencionou que o empreendedor "busca inovar e ter um diferencial", o que evidencia a importância de focar os estudos do empreendedorismo em "como" identificar oportunidades e em "como" desenvolver o processo criativo dos estudantes.

Para a prática do ensino do empreendedorismo, os relatos dos alunos entrevistados evidenciam que "saber identificar uma oportunidade" ou saber "ler" o mercado são habilidades importantes a serem desenvolvidas, e para um dos professores entrevistados um curso de empreendedorismo deve "investir muito na pessoa, na criatividade e no senso de oportunidade do mercado".

Merece destaque, a demanda apresentada por um dos alunos entrevistados sobre o acesso "à incubadora de empresas, o que permitiria ficar melhor preparado para iniciar um negócio". Este relato encontra amparo em Antonello e Dutra (2005) e, em Godoy e Antonello (2009), ao argumentarem que a experiência vivida (e que pode ser propiciada pela incubadora) é um poderoso instrumento de aprendizagem.

As características de um empreendedor, na visão dos alunos entrevistados, transitaram entre conhecimentos, atitudes e habilidades extensamente difundidas na literatura (CUNNINGHAM; LISCHERON, 1991; FILION, 1999, entre outros autores). Foram identificadas em $66 \%$ das respostas dos alunos entrevistados características como saber inovar, identificar oportunidades e ser criativo, conforme os extratos das entrevistas: 
Criatividade, pessoa que corre riscos, que inova, busca recursos, tenta mudar o meio, tenta buscar inovações que vão agregar conhecimentos, fazer o que gosta e melhorar o ambiente em que trabalha (Aluno1).

A principal característica que um empreendedor tem que ter é a capacidade de assumir riscos calculáveis [...] Saber identificar oportunidades e ter liderança [...] estar sempre buscando melhorias e observando a situação, ter criatividade e buscar inovar (Aluno 4).

Trata-se de características que, se não inerentes a uma pessoa, conforme Hisrich, Peters e Shepherd (2009) podem ser aprendidas e desenvolvidas como qualquer outra habilidade. Outras características como saber influir, persuadir, liderar e, ainda, relacionar e negociar, também apareceram em 33\% das respostas dadas pelos alunos entrevistados.

As características comportamentais empreendedoras, na visão de um dos professores entrevistados, podem ser distribuídas em três conjuntos: de realização, planejamento e poder, conforme visto em Greatti e Senhorini (2000). O primeiro permite às pessoas ousar "saírem do sonho à realidade", além de aperfeiçoar sua persistência, seu comprometimento e a busca por oportunidades; o segundo está relacionado ao planejamento, em que se determinam os objetivos, as metas, aonde se pretende chegar; o terceiro está relacionado ao poder que se desenvolve nas relações interpessoais, no networking, no poder de convencimento. Os outros três professores entrevistados referiram-se a uma pessoa que assume riscos, que é criativa, persistente e ousada. Dessa forma, as características comportamentais dos empreendedores citadas pelos professores fazem coro com aquelas relatadas pelos alunos entrevistados e com aquelas apresentadas na literatura por Greatti e Senhorini (2000).

Embora os empreendedores possam ser vistos como individualistas e o empreendedorismo em equipe seja pouco difundido, na realidade a associação entre empreendedores é uma estratégia para reduzir riscos, reunir competências e recursos materiais e financeiros. Novamente, esta é uma questão importante e possível de ser trabalhada com os alunos (BRUSH; HART; GREENE, 2002).

Sobre a questão relacionada ao ensinamento do empreendedorismo, 53\% dos alunos entrevistados reconhecem ser possível a aprendizagem, enquanto $20 \%$ defendem que a pessoa também "nasce" empreendedora. Outros 13\% afirmaram que o empreendedorismo pode ser ensinado com a condição de que as pessoas empreendedoras apresentem um perfil adequado ao aprendizado, podendo ser estimulado:

Eu acredito que sim, pode ser ensinado e também o que motiva uma pessoa a se tornar empreendedora é o meio em que ela vive [...] acredito também que possa ser ensinado na faculdade (Aluno 4). 
Com certeza pode ser ensinado [...] Alguns já nascem com dom empreendedor. Observando pessoas no mercado, tem pessoas que têm já aquela vocação, já desde mais novo para o empreendedorismo. Mas ao mesmo tempo, em contrapartida, o curso de Administração demonstra que ele pode ser aprendido, sim (Aluno 7).

Pode. A pessoa pode aprender. Você pode ter habilidade antes de aprender. Mas quando você começa a entender o que é o empreendedorismo e que você busca informações sobre ele, aí você aprende, você passa a ser empreendedor [...] (Aluno 12).

Somente dois dos quinze alunos entrevistados argumentaram que o empreendedorismo não pode ser ensinado e que a pessoa nasce com o espírito empreendedor, conforme se observa no extrato da entrevista:

Eu acho que ele pode ser assim, motivado, melhorado, mas ensinado, eu acho que pode tentar ensinar, mas o perfil tá em primeiro lugar, se não for uma pessoa que tem aquela ânsia de fazer, eu acho que não rola não [...] (Aluno 5).

Dos quinze alunos entrevistados, onze pretendem desenvolver um negócio próprio. Porém, efetivamente cerca de um terço do total, ou seja, cinco, pretendem fazê-lo em curto e médio prazo, buscando-se as ações para tal.

Por outro lado, 27\% dos alunos entrevistados afirmaram que por meio do curso descobriram a intenção empreendedora, argumentando que anteriormente ao curso "não via possibilidade nenhuma de empreender" (Aluno 13). A maioria dos alunos entrevistados (53\%) reconhecem que a graduação em Administração contribui para o desenvolvimento futuro do empreendedor, despertando a vontade de empreender e proporcionando uma preparação com objetividade.

[...] a gente vai tomando conhecimento, se aprofundando sobre a administração, sobre os negócios, sobre a possibilidade de empreender ou a possibilidade de administrar. Pode tanto seguir a carreira executiva dentro de uma empresa ou outra possibilidade, a carreira empresarial, abrir meu próprio negócio (Aluno1).

Segundo Flores (2007), os alunos do curso de Administração lidam com conceitos, formas organizacionais e toda uma "carga" de conhecimentos e estratégias próximas à formação e à gestão de empresas, permitindo que sejam aplicadas tanto nas organizações de terceiros, quanto em uma própria.

Verificou-se, ainda, que $35 \%$ dos alunos entrevistados atribuem às disciplinas cursadas, o aperfeiçoamento e a potencialização da capacidade empreendedora, pois haviam ingressado no curso com este propósito. Quanto à percepção de confiança para empreender 
individualmente ou em parceria após a formação recebida, 73\% dos alunos entrevistados responderam positivamente, inferindo que iniciariam um negócio próprio.

De outro lado, percebeu-se dificuldades encontradas pelos alunos entrevistados para empreender, após cursar as disciplinas sobre empreendedorismo. Algumas delas como vivenciar a prática e não ter o capital necessário, altos impostos e burocracias ganharam mais ênfase nos relatos dos alunos. Todavia, lembraram que somente conheceriam as reais dificuldades exercendo o empreendedorismo efetivamente, além da questão do "mercado saturado".

Na percepção dos professores entrevistados, as dificuldades encontradas pelos alunos se resumem na falta de dedicação aos estudos por parte de alguns; ter que conciliar o trabalho, o estudo e a família; a falta de recursos financeiros; imaturidade, além da cultura da região.

Em relação ao ensino do empreendedorismo, os alunos que concordam com esta possibilidade afirmam que o aprimoramento da aprendizagem pode ser obtido por meio de práticas empreendedoras, durante a graduação. A maioria dos alunos entrevistados (60\%) mencionaram que o curso deve dar ênfase à prática: "ser voltado à prática ou vivenciar situações próximas às reais" com "mais laboratórios, jogos e dinâmicas". Outros 13\% sugeriram cursar a disciplina "Plano de Negócios" antes de participar da "Empresa-Ação" e ainda, 7\% “disponibilizar a Empresa-Júnior e/ou Incubadora de Empresas, argumentando que o ensino deve ter mais práticas empreendedoras, criar projetos relacionados e ter o foco em inovação.

A ênfase dada pelos alunos entrevistados de que o ensino do empreendedorismo deve ser voltado à prática está de acordo com os argumentos de Ferreira e Matos (2003) e, de forma análoga, com os resultados da pesquisa de Martens e Freitas (2008), que demonstrou maior interesse dos estudantes por atividades práticas.

Além disso, os alunos entrevistados observaram que as temáticas sobre o empreendedorismo não devem ser tratadas de forma ampla, embutida no curso, mas sim, aprofundadas por meio de disciplinas específicas, criando projetos e práticas que os estimulem.

[...] poderia ter uma matéria específica por que quando a gente vê o empreendedorismo aqui nesta faculdade, a gente o vê embutido em outras matérias e se a pessoa não tem um feeling pra pegar isso, ela não consegue se tornar um empreendedor (Aluno 4). 
Para os professores entrevistados as estratégias a serem adotadas para o ensino do empreendedorismo alinham-se ao argumento dos alunos em alguns pontos como, por exemplo, propiciar a participação em dinâmicas e em jogos de empresas. Complementam ainda, que o curso deve ser focado, principalmente, na pessoa, no "senso de oportunidade", de forma a conduzir os alunos para o conhecimento e hábito de leituras sobre as histórias de empreendedores de sucesso, focando, também, no autodesenvolvimento, reconhecendo as próprias habilidades, deficiências e como superá-las. Citaram, também, o desenvolvimento de habilidades relacionais, de negociação, de comunicação e de informação, como forma de proporcionar o aprendizado prático e adaptação às novas tecnologias, trabalhar a capacidade criativa e de inovação com o aluno.

Quanto ao desenvolvimento da postura empreendedora, as características de proatividade, persistência, criatividade e inovação são reconhecidas tanto pelos alunos quanto pelos professores entrevistados como necessárias, de acordo com os atributos identificados e amplamente difundidos na literatura.

Em síntese, as posições identificadas na percepção dos alunos e dos professores entrevistados podem ser assim destacadas: a) para os alunos deve-se incluir na práticapedagógica maior tempo e espaço para vivência prática do ensino; b) criar mecanismos de apoio financeiro para as atividades práticas do empreendedorismo como parcerias, financiamentos, doações; c) criar uma incubadora de empresas ou implantar a EmpresaJúnior; d) para os professores, os alunos devem desenvolver e adotar atitudes, em regra, verificáveis em empreendedores, como a criatividade e a busca pela inovação; e) buscar os conhecimentos por meio de leituras, contatos com empreendedores e estabelecimento de redes de contatos.

\section{CONSIDERAÇÕES FINAIS}

O objetivo desta pesquisa foi analisar se a prática didático-pedagógica adotada no curso de Administração para o ensino do empreendedorismo interfere na propensão a empreender do ponto de vista de alunos e de professores de uma Instituição de Ensino Superior, localizada na região do Vale do Aço-MG. Condicionado à complexidade das dimensões analisadas evidenciou-se, pelos relatos dos entrevistados, que as práticas oferecidas aos alunos durante o curso, notadamente quanto à aplicação prática dos conceitos 
teóricos estudados, parecem propiciar condições ao processo empreendedor, confirmando assim, a corrente teórica que apóia a possibilidade do ensino do empreendedorismo.

Quanto à disposição e intenção para empreender há indícios de que, para o aprendizado ser efetivo, há que se exercitar mais as práticas empreendedoras no ambiente educacional, pois, 53\% dos alunos entrevistados não descartam a possibilidade de criar o próprio negócio.

Como facilidades para empreender apontam-se a possibilidade de aplicação dos conhecimentos teóricos adquiridos, o aprendizado quanto à análise e avaliação do mercado e o desenvolvimento da "visão de oportunidades". De outro lado, tem-se como dificuldades o fato de ter que vivenciar a prática, lidar com a falta do capital necessário, conviver com os impostos, a burocracia e a falta de maturidade, além de ter que enfrentar o desafio imposto pela cultura regional.

Verificou-se, também, que o ensino do empreendedorismo é dependente de uma estrutura de apoio por meio da qual os alunos possam desenvolver atividades práticas empreendedoras como é o caso da Empresa-ação, dinâmicas e jogos de empresas corroborando a posição de autores como Dolabela (1999); Schmidt, Domingues e Hoeltgebaum (2005); Souza e Guimarães (2006); Martens e Freitas (2008).

Com o ensino do empreendedorismo e as possibilidades das diversas práticas escolares há um efeito desmistificador sobre o empreendedor e empreendedorismo. Há, também, contribuição a compreensão de que, para tornar-se empreendedor é necessário um trabalho persistente, formação de parcerias e a integração de recursos. São ações efetivas que superam fatores como "sorte" ou "nascer empreendedor" abrindo-se perspectivas para escolhas mais conscientes por parte dos graduandos relativas às próprias carreiras.

Diante do exposto, considera-se que há indicações de que o empreendedorismo pode ser ensinado e praticado como modo de formação e qualificação e as características e as habilidades requeridas podem ser desenvolvidas e aprendidas como qualquer outra habilidade, conjugando-se a teoria e a prática.

Do ponto de vista institucional faz-se necessário a adoção de mecanismos de apoio ao ensino, a realização de parcerias entre os atores institucionais privados e públicos, como os órgãos de fomento, empresas de transferência de tecnologia ofertando condições estruturais, além das incubadoras. Além disso, deve-se criar e facilitar acesso a financiamentos esta 
finalidade, realizar as adequações legais e fiscais exigidas e de infraestrutura como políticas públicas e governamentais para estimular o espírito empreendedor.

A pesquisa evidenciou, no aspecto exemplificado, que o ensino do empreendedorismo deve ser integrativo no qual os educandos tenham primeiro, contato com os fundamentos teóricos de suporte para a realização do "plano de negócios", facilitando a apreensão e aplicação dos conceitos no momento em que for realizar a disciplina.

Sugere-se enfatizar aos estudantes a possibilidade de empreender em equipes estimulando-os a fazerem associações entre os próprios colegas, familiares ou terceiros reunindo recursos financeiros, humanos e de conhecimentos.

Pensar em limitar a ação empreendedora, no âmbito da criação de negócios, pela falta de recursos financeiros nem sempre é o mais correto, pois essa condição pode ser superada por meio de associação entre pessoas, utilização de infraestrutura a baixo custo como as incubadoras de empresas, pela busca por agentes financiadores com uma proposta atrativa, conforme preceitua Luecke (2010).

Outro aspecto importante a ser destacado quanto ao ensino do empreendedorismo nos moldes indicados é que ele proporciona ao educando uma visão do contexto em que estão inseridos, abrindo-se possibilidades de formar um profissional com competências adequadas à realidade. Este estímulo apresenta aos alunos suas variadas perspectivas, porém de forma sistematizada e estruturada.

Ao se propor um ensino com o foco no empreendedorismo sugere-se implantar conjuntamente um sistema de avaliação de seus resultados que poderia ser, por exemplo, o acompanhamento dos ex-alunos ao longo do tempo.

Outra ideia a ser desenvolvida com os alunos é a perspectiva do empreendedor inovador trazida por Schumpeter (1997). Não a inovação per si, a que promove a obsolescência de processos e produtos, mas a que assegura que as mudanças tenham sempre em vista a redução do impacto humano sobre o meio ambiente e a inclusão de novas perspectivas.

Talvez a relativa desconfiança no ensinamento formal do empreendedorismo e no seu desenvolvimento teórico relativamente recente seja fruto de os mesmos não terem alcançado, ainda a maturidade e, na medida em que ocorrerem a sua disseminação, evolução, apoio às práticas de ensino e de pesquisas, este quadro tende a se alterar. 
Considera-se como limitação deste estudo o fato de ter sido realizado em apenas uma instituição de ensino. Entretanto, isso não invalida a sua realização uma vez que se valeu de várias fontes de evidências como alunos, professores, o projeto pedagógico do curso, além de ementas das disciplinas. Desse modo, sugerem-se como estudos futuros ampliá-los em múltiplas instituições de ensino, em número e grupo de entrevistados, podendo ainda ser completado com um estudo quantitativo, fazendo-se um levantamento acerca do ensino do empreendedorismo.

Uma vez que resultados mais robustos não se evidenciam em curto prazo, sugere-se também a realização de estudos longitudinais com profissionais após dois ou três anos de formados e estudos relacionando o aprendizado do empreendedorismo versus fomento, créditos.

Outro aspecto a ser pesquisado é a influência da cultura empreendedora local no direcionamento profissional dos alunos graduados e estudos que evidenciem a importância do plano de negócios para empresas iniciantes, visando aprofundar ainda mais o conhecimento sobre o empreendedorismo, além do desenvolvimento de uma ação formadora e educacional.

\section{REFERÊNCIAS}

ALVES-MAZZOTTI, A. J.; GEWANDSZNAJDER, F. O Método nas ciências naturais e sociais: pesquisa quantitativa e qualitativa. 2. ed. São Paulo: Pioneira, 2004. 203 p.

ANDREASSI, T.; FERNANDES, R. J. R. O uso de competições de planos de negócios como ferramenta de ensino de empreendedorismo. In: Rose Lopes, Mary A. (Org.). Educação empreendedora: conceitos, modelos e práticas. Rio de Janeiro: Elsevier, 2010. p. 193-205.

ANTONELLO, C. S.; DUTRA, M. L. S. Projeto Pedagógico: uma proposta para o desenvolvimento de competências de alunos do curso de Administração, com foco em empreendedorismo. In: XXIX ENCONTRO NACIONAL DE PÓS-GRADUAÇÃO EM ADMINISTRAÇÃO, 2005, Brasília. Anais... Rio de Janeiro: ANPAD, 2005. p. 561.

BERTALANFFY, L. V. Teoria Geral dos Sistemas. Petrópolis. Rio de Janeiro: Vozes, 1973.

BORGES, C.; FILION, L. J.; SIMARD, G. Jovens empreendedores e o processo de criação de empresas. In: V ENCONTRO DE ESTUDOS SOBRE EMPREENDEDORISMO E GESTÃO DE PEQUENAS EMPRESAS, 2008, São Paulo. Anais... São Paulo: EGEPE, 2008. Disponível em: <http://www.faccamp.br/apoio/OdairSilva/empreendedorismo/196_tra balho-jovens_empreendedores.pdf $>$. Acesso em: 23 maio 2010. 
BRUSH, C. G.; HART, M. M.; GREENE, P. G. Empreendedorismo e construção da base de recursos. Revista de Administração de Empresas. São Paulo: ed. FGV, v. 42, n.1, 2002. p. $20-35$.

CHIZZOTI, A. A pesquisa qualitativa em ciências humanas e sociais: evolução e desafios. Revista Portuguesa de Educação. Universidade do Minho, Braga, Portugal, [s.n.], v. 16, n. 2, 2003. p. 221-236.

CUNNINGHAM, J. B.; LISCHERON, J. Defining Entrepreneurship. Journal of Small Business Management. [s.1.], Blackwell Publishing Limited, v. 29, n.1, 1991, p.45-67.

DAVID, D. E. H. et al. Aspectos pedagógicos no ensino do empreendedorismo. In: III ENCONTRO NACIONAL DE EMPREENDEDORISMO, 1, 2001. Anais... ENEMPRE, 2001. Disponível em: $<$ http://www.daeln.ct.utfpr.edu.br/ denisedavid/artigos_textos/aspectos pedagogicos.pdf $>$. Acesso em: 05 maio 2010.

DOLABELA, F. Entrevista. 2010. Disponível em: < http://naniedias.blogspot.com/2010/08/ entrevista-fernando-dolabela.html >. Acesso em: 22 dez. 2010.

DOLABELA, F. Oficina do empreendedor. São Paulo: Cultura, 1999.

DOLABELA, F. O segredo de Luisa. 30 ed. São Paulo: Editora de Cultura, 2006. 304 p.

DOLABELA, F. Programas aprendendo a empreender. Ensino de empreendedorismo no Brasil: uma metodologia revolucionária. 2008. Disponível em: <http://www.projetoe.org.br/ tv/prog10/html/ar_10_01.html>. Acesso em: 12 jan. 2010.

DRUCKER, P. F. Inovação e espírito empreendedor (entrepreneurship): prática e princípios. São Paulo: Cengage Learning, 2008. 378 p.

FERREIRA, P. G. G.; MATTOS, P. L. C. L. Empreendedorismo e práticas didáticas nos cursos de graduação em administração: os estudantes levantam o problema. In: ENCONTRO NACIONAL DA ASSOCIAÇÃO NACIONAL DOS CURSOS DE PÓS-GRADUAÇÃO EM ADMINISTRAÇÃO, 27., 2003, Atibaia. Anais... Atibaia: ANPAD, 2003.

FERREIRA, J. M.; RAMOS, S. C.; GIMENEZ, F. A. P. Estudo comparativo das práticas didático-pedagógicas do ensino de empreendedorismo em universidades brasileiras e norteamericanas. Revista Alcance - Univale, v. 13, n.2, p. 207 - 225, maio/ago 2006. Disponível em: < http://siaiweb06.univali.br/seer/ index.php/ra/article/viewFile/161/133 >. Acesso em: 17 jan. 2010.

FILION, L. J. Um roteiro para desenvolver empreendedorismo. Carte rutière pour um Québec entrepreneurial. HEC Montreal. Riverin, 2003, p.37-38. Disponível em:

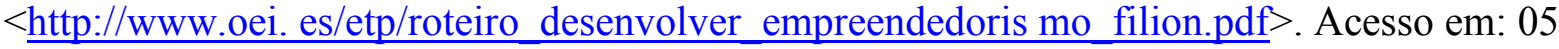
nov. 2009.

FILION, L. J. Empreendedorismo: empreendedores e proprietários-gerentes de pequenos negócios. Revista de Administração da Universidade de São Paulo - RAUSP. São Paulo, 
Edusp, v. 34, n. 2, p. 05-28. abr/jun. 1999. Disponível em: <http://www.dge. ubi.pt/msilva/OE OGE/ Empreendedorimo.pdf. Acesso em: ago. 2011.

FLORES, D. C. O ensino do empreendedorismo nos cursos de pós-graduação em Administração no Brasil. 184 f. Dissertação (Mestrado em Administração) - Universidade Regional de Blumenau. Centro de Ciências Sociais Aplicadas. Blumenau. 2007. Disponível em: $<$ http://proxy.furb.br/tede/tdearquivos/2/TDE-2007-10-09T123141Z-339/Publico/Diss\% 20Danusa\%20Cunha\% 20Flores.pdf>. Acesso em: 28 dez. 2010.

GEM - Global Entrepreneurship Monitor. Empreendedorismo no Brasil. Relatório Executivo. Curitiba. 2009. Disponível em: $<$ http://www.biblioteca.sebrae.com.br/bds/BDS .nsf/EB026BCD4EC54332832576FC0072BFC4/\$File/NT00043D8E.pdf >. Acesso em: 08 set. 2010.

GEM - Global Entrepreneurship Monitor. Empreendedorismo no Brasil. Relatório Executivo. IBPQ, 2012. Disponível em: $<$ http://bis.sebrae.com.br/GestorRepositorio/ARQUI VOS_CHRONUS/bds/bds.nsf/9696c98c23d137fd0d8af1300d9742b0/\$File/4226.pdf $>$. Acesso em: 03 jul. 2013.

GODOY, A. S.; ANTONELLO, C. S. Competências individuais adquiridas durante os anos de graduação de alunos do curso de administração de empresas. Revista de Ciências da Administração. Florianópolis, Santa Catarina: UFSC, v. 11, N. 23, p. 134-156, jan/abr. 2009.

GREATTI, L.; SENHORINI, V. M. Empreendedorismo - uma visão comportamentalista. In: I ENCONTRO DE ESTUDOS SOBRE EMPREENDEDORISMO E GESTÃO DE PEQUENAS EMPRESAS, 2000, Maringá. Anais... Maringá: EGEPE, 2000. Disponível em: $<$ http://www.egepe.com.br/geral/arquivos/edicoesAnteriores/IEGEPE2000/EMP2000-01.pdf> Acesso em: 17 jul. 2011.

HISRICH, R. D.; PETERS, M. P.; SHEPHERD, D. A. Empreendedorismo. 7. ed. Porto Alegre: Bookman, 2009. 664 p.

LUECKE, R. Ferramentas para empreendedores. 4. ed. Rio de Janeiro: Ed. Record. 2010. MACULAN, A. M. Analisando o empreendedorismo. In: IV ENCONTRO DE ESTUDOS SOBRE EMPREENDEDORISMO E GESTÃO DE PEQUENAS EMPRESAS, 2005, Curitiba. Anais... Curitiba: EGEPE, 2005.

MARTENS, C. D. P.; FREITAS, H. Influência do ensino de empreendedorismo nas intenções de direcionamento profissional dos estudantes. Revista Estudo \& Debate. Lajeado, Rio Grande do Sul: [s.n.], v. 15, n. 2, 2008. p. 71-95.

MELO, M. C. O. L. et al. Em busca de técnicas complementares em pesquisa qualitativa no campo da administração. In: Garcia, F. C. G.; Honório, L. C. Administração, metodologia, organizações, estratégia (Coord.). 2 ed. Curitiba: Juruá. 2007.

MELO, M. C. O. L. et al. Empreendedorismo e o papel das incubadoras para as empresas graduadas de base tecnológica da região metropolitana de Belo Horizonte. In: XII 
SEMINÁRIO EM ADMINISTRAÇÃO, 2009, São Paulo. Anais... São Paulo: SEMEAD, 2009.

MEURER, V. O perfil empreendedor do empresário da área da saúde: estudo exploratório com empresários de Maringá. Maringá. Paraná. 2003. Disponível em: $<$ http://www.ppa.uem.br/ defesas/pdf/dis029.pdf>. Acesso em: 30 ago. 2010.

OLIVEIRA, J. M. A construção de um ambiente empreendedor dentro das universidades.

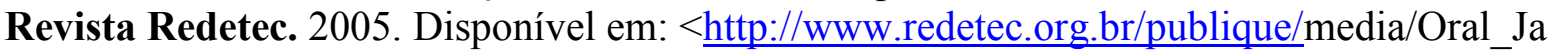
naina\%20Mendes\%20de\%20Oliveira.pdf $>$. Acesso em: 15 mar. 2010.

OLIVEIRA, J. M. Modelo para a integração dos mecanismos de fomento ao empreendedorismo no âmbito das universidades: o caso da Universidade Federal do Rio Grande do Sul. 182 f. Tese (Doutorado em Engenharia da Produção) - Programa de PósGraduação em Engenharia de Produção, Universidade Federal de Santa Catarina, Florianópolis. 2006. Disponível em: <http://www.tede.ufsc.br/teses/PEPS4992.pdf $>$. Acesso em: 05 mai. 2010.

PEREIRA, R. L. A. As competências do educador na difusão da cultura empreendedora: uma análise no ensino fundamental e superior de Belo Horizonte. $124 \mathrm{f}$. Dissertação (Mestrado Profissional em Administração) FIPEL - Fundação Cultural Dr. Pedro Leopoldo Faculdades Integradas de Pedro Leopoldo, 2010.

PESSOA, E.; GONÇALVES, S. M. G. Ensino de empreendedorismo: uma abordagem tridimensional. 2004. Disponível em: $<$ http://www.icesi.edu.co/ciela/anteriores/Papers/edem /1.pdf>. Acesso em: 22 ago. 2010.

PPCGA. Projeto pedagógico do curso de graduação em Administração do Centro Universitário do Leste de Minas Gerais - UNILESTE. Coronel Fabriciano (MG), 2010. $111 \mathrm{p}$.

RESENDE, L. M.; DIB, S. K.; LEITE, M. G. Gestão Empreendedora de Carreiras Tecnológicas. Revista Gestão Industrial. v. 1, n. 1, 2005. p. 37-48. Disponível em: $<$ http://www.pg.utfpr.edu.br/depog/periodicos/index.php/revistagi/article/view/175/171>. Acesso em: 28 dez. 2010.

SARAIVA, L. A. S.; SOUZA, Â. M. DE. Representações sociais, práticas e desafios do ensino de empreendedorismo na graduação sob a ótica dos docentes: um estudo de caso. In: ENCONTRO NACIONAL DE ENSINO E PESQUISA EM ADMINISTRAÇÃO E CONTABILIDADE, 134., 2009, Curitiba. Anais... Curitiba: EnEPQ, 2009.

SCHUMPETER, J. A. Teoria do desenvolvimento econômico: uma investigação sobre lucros, capital, crédito, juro e o ciclo econômico. São Paulo: Nova Cultural. 1997.

SCHMIDT, C. M.; DOMINGUES, M. J. C. S.; HOELTGEBAUM, M. Ensino de Empreendedorismo: uma análise nos cursos de administração das IES de Blumenau/SC. In: V COLÓQUIO INTERNACIONAL SOBRE GESTIÓN UNIVERSITARIA EM AMÉRICA DEL SUR, 2005, Mar del Plata. Anais... Mar del Plata: 2005. 
SEBRAE. Taxa de sobrevivência das empresas no Brasil. Coleção Estudos e Pesquisas, outubro. 2011.

SOUZA, E. C. L. et al. Métodos, técnicas e recursos didáticos de ensino do empreendedorismo em IES brasileiras. In: Souza, E. C. L. de; Guimarães, Tomás de A. (Org.). Empreendedorismo além do plano de negócio. São Paulo: Atlas, 2006. p. 200-216.

SOUZA, E. C. L.; GUIMARÃES, T. A. O ensino de empreendedorismo em instituições de ensino superior brasileiras. In: SOUZA, E. C. L.; GUIMARÃES, T. A. (Org.).

Empreendedorismo além do plano de negócio. São Paulo: Atlas, 2006. p. 241-259.

UNILESTE - Centro Universitário do Leste de Minas Gerais - Projeto pedagógico do curso de graduação em administração. Coronel Fabriciano-MG, 2010. 111 p. 